\title{
Enhancing Due Diligence - Examination Of The Organisational Culture Of A Merger And Acquisition Target
}

Grant Jones, (Email: grant.jones@mgsm.edu.au), Macquarie University, Australia

\begin{abstract}
A set of indicators are derived from elements of theory on organisational culture, which will assist managers to make judgements about the internal culture of a potential target for merger or takeover.
\end{abstract}

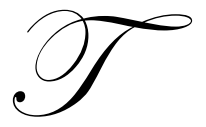

he early part of this decade saw a wave of merger and acquisition activity that is unprecedented in human history. For many CEOs merger and acquisition constitutes the growth strategy for the company and hence their whole focus. But when a company buys another company with the object of integrating it into the common structure, what is it actually buying? "Due diligence" is a term that describes the process by which a buyer checks that value of a prospective purchase. The term has a deceptively comforting connotation that information is assembled methodically and gives a comprehensive picture of the target for acquisition. Unfortunately, most of what the company is buying is intangible and invisible. Intangible assets include the company's store of knowledge and leadership and both these assets are encoded in the company's culture.

Getting a picture of the target company's culture is complicated by the very complexity of culture itself. Culture is inherently difficult to assess from the outside. In order to make some sort of evaluation as to whether the two organisations are compatible, the analyst must get inside the company and engage in the kind of reflective participant observation that enables a rich and deep understanding of the currents and eddies, differentiated sub cultures and ambiguities within the culture. Getting a clear picture of the health of a target company is often complicated by the fact that the target may have little interest in providing information on tangible assets and much less interest in helping predators see the less visible assets. Yet, it is the people that come with the company that can either make or break the synergies that are supposed to be created by the merger or takeover.

This paper draws on elements of the theory of organisational culture to develop a small suite of tangible, visible indicators of an organisation's culture that can be observed from the outside. These are designed to enable some estimation of cultural complementarity, even during a hostile takeover where access to information on the internal life of the organisation is denied. The takeover of a smaller company by Microsoft is then cased as a means of illustrating both the principles of cultural inference and the utility of the indicators in clarifying organisational culture.

Figure 1 demonstrates the waves of merger and acquisition that have occurred over the past four decades. Hyper competition, sustained economic growth and the availability of capital have lead organisations to try to grow through acquisition. There is also an association between the rise and fall in levels merger and acquisition activity and economic cycles, which is more or less observable from the graph: increasing activity can be observed during the growth periods leading up to 1972, 1987 and 2002. Merger and acquisition activity then tends to drop away with recessionary periods that follow growth spurts. 
Figure 1 Value of Mergers and Acquisitions 1965-2004

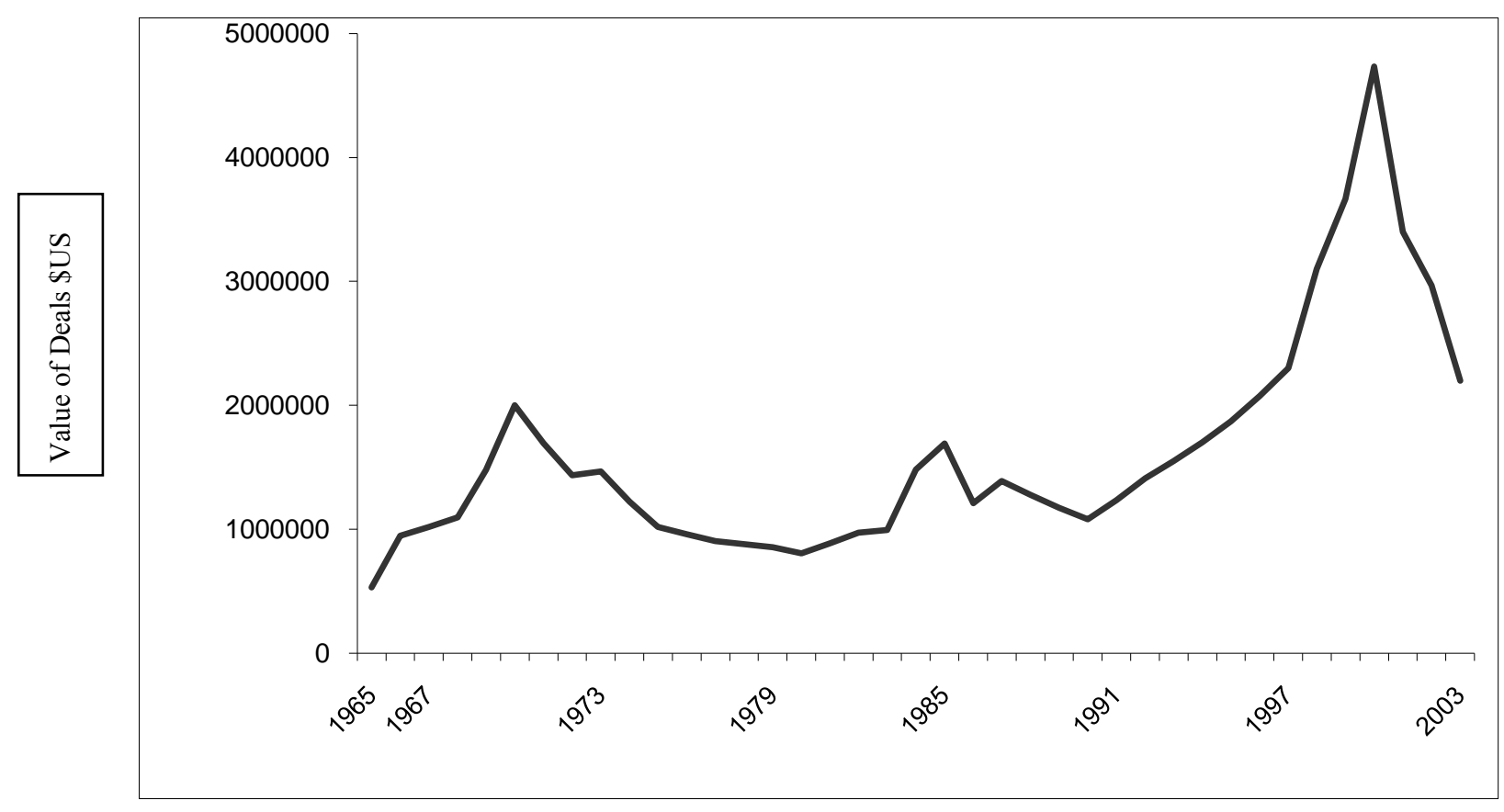

Research on mergers and acquisitions shows that, more often than not, they fail to achieve their objectives and are followed by falls in the market value of the firms that have initiated the takeover (Kay and Shelton 2000). Part of the secret to this damage may lie in the erosion of intangible assets because of a failure to properly maintain the intangible dimension of the organisation's asset base throughout the process. Accountants are currently revising the assessment of the value of the organisation's asset base to take better account of the value of intangible assets. These are the invisible assets of the firm, which are real enough to generate a revenue stream. Baruch Lev has suggested that we can evaluate intangible assets by simply deducting the value of visible or tangible assets from the market capitalisation of the company. His work estimates that the average proportion of the value of the asset base of companies in the United States that is intangible is about 85\% (Lev 2001).

When a company buys another company, most of what it is buying is intangible and difficult to observe and evaluate. Intangible assets include the knowledge, capacity for innovation and leadership of the organisation. A recent survey suggested that 4/5 new jobs being created in the OECD are either based on the use of sophisticated knowledge or the creation of knowledge (Arnal, Ok and Torres 2001). Knowledge workers expect to be able to innovate and to be given the opportunity to do so. They are not satisfied with the repetition of dull process and they value creativity. More importantly, they are empowered by the fact that they hold the company's primary asset inside their heads and take it home with them every night after work (Drucker 1998). Such workers are likely of be particularly sensitive to changes in organisational culture, because knowledge is embedded in culture. They will be looking for a kind of culture which acknowledges and validates the kind of knowledge that they produce.

Capacity for innovation, including knowledge and leadership, is bound up in the culture of the organisation. Yet the practice of looking at culture as part of the due diligence process is not widespread. A survey of 190 CEOs and CFOs involved in mergers and acquisitions worldwide over 1998/1999 period by Watson Wyatt research found that only $46 \%$ had examined the "organisational culture and dynamics of change." as opposed to $90 \%$ who had examined the "hard assets" of the company in question. Even where the need to get data on culture is accepted, the science or art of what one is to look for is crude, and companies that do so are not sharing their metrics. It is then perhaps not surprising that the literature is relatively free of showcases of promising practice. 
The so-called excellence literature highlights the central importance of strong corporate culture to organisational profitability (see for example Peters and Waterman 1982; Kotter and Heskitt 1992, Collins and Porrass 1996; Deal and Kennedy 1988 and 2000). Deal and Kennedy suggest that the critical determinant of business culture is the business model. The two variables inherent in the business model that they cite as determining cultural outcomes are the amount of risk and the speed of feedback. The importance of this finding to the central problem that this paper addresses is that both these variables can be observed from the outside. We need only the most rudimentary information on what the business actually does in order to be able to process that information into a prediction as the nature of the organisational culture.

Figure 2 - The Impact of the business model on emergent culture

\begin{tabular}{|c|c|c|}
\cline { 2 - 3 } & \multicolumn{1}{c|}{$\begin{array}{c}\text { Bet Your Company } \\
\text { Eg Exploration company }\end{array}$} & Tough guy - macho \\
Eg Film production company
\end{tabular}

\section{Deal and Kennedy's Cultures}

The Tough-Guy, Macho: values speed and the taking of action. These cultures welcome high-pressure work and are proud of their ability to cope with it. Individuals will take personal career risks to achieve outcomes.

Work Hard/Play Hard: values customers and their needs. They also like to take action and value initiative, but they want activity to continuous, chafing during periods of down time.

Bet-Your-Company: has high-risk tolerances, but values meetings as a way of making these high risks well considered. The focus is on the future and the importance of investment.

The Process Culture: values technical perfection, detail and accountability for getting decision making right. The value on rational decision-making implies an associated value on reliable evidence.

An important implication of the model is that if an organisation is determined to acquire a business that is likely to produce a process model and then incorporate it with, say, a tough guy macho model then two questions arise: can the buying organisation change the fundamentals of one or both of the organisations that are to merge; or alternatively what assurance is there that the two elements of your hybrid business are can cooperate as vastly different subcultures.

The excellence literature has been criticised for its simplistic notions of culture and for treating culture as the object of management rather than the way that management has been done (Smircich 1983). Martin and Meyerson (1988) and Martin (1992) have taken the argument further to define various perspectives though which culture can be observed, perspectives that suggest that culture can only really be understood by understanding its complexity. This complexity includes the various decision making processes and the ambiguities and even ironies inherent in the ways in which work is accomplished within the organisation.

Martin and Meyerson (1988) coined the term "the differentiation perspective" to define the tendency for people studying cultures to bypass the unifying, commonly shared elements of an organisational culture and seek out the points of inconsistency that differentiate cultural streams within a single organisation. These inconsistencies 
could include differences between stated attitudes and real behaviour or between formal practices and informal norms, between what is made obvious and talked about openly and what remains implicit and covert.

Sometimes different cultures within an organisation define differing views of what may be the appropriate functions of that organisation. The conflict between these views may remain unresolved and the proponents may succeed in instituting these separate functions, which in turn generate their own subcultures. This process could be observed in action in a church which accommodates sects or orders, each with differently defined dedications, or a police department were officers may be attracted to a social service role (community based policing), an investigation role (detectives) or an enforcement role (tactical flying squads). Sometimes the subcultures are seen to be internally integrated, but to lie in a natural opposition to other sub-cultures. Sometimes the sub-cultures are seen as overlapping. The bigger picture may be one of productively competing sub-cultures or of the emergence of destructive politics where sub-cultures compete with one another for scarce organisational resources.

Martin later identified a third perspective, the "fragmentation perspective" which seeks out data on the ambiguities within a culture (Martin 1992). Those looking through a fragmentation lens are only interested in the currents of mainstream culture in order to find points of fracture, mixed or confused feelings. Consensus is neither organisation-wide nor does it have a separate existence in each subculture. It is transient. Affinities between people are issue specific. They dissolve and are replaced by new affinities as new issues become prominent. Clarity is an illusion created by management, but the reality is a confusion of beliefs and mixed reactions that people feel to what is going on about them (Levitt and Nass 1989).

This level of detailed scrutiny cannot easily be accomplished from the outside of the company. However, an awareness of ambiguity, differentiation and fragmentation could lead us to look for evidence of the lines of differentiation and the points of ambiguity in what is visible. Instead of dismissing inconsistent information because we assume that the information must be inaccurate, we might instead see the information as a test for the existence of ambiguity or differentiation. Deal and Kennedy's latest work (Deal and Kennedy 2000) also acknowledges the differentiation perspective by suggesting that a single organisational culture might have multiple business models, which in turn lead to emergence of differentiated subcultures.

We can turn the theory traversed in this paper to practical effect by deriving a series of indicators against which a company can be "audited". The task performed by Figure 3 is to find indicators which can be observed from the outside, which will give us some sense of the likely internal culture of the organisation, in the absence of privileged access to the internal workings of the firm or its employees. These indicators provide a basis for judgement and are no substitute for systematic observation from inside the company. They are designed to cope with the contingency that the means of more systematic internal observation are simply not available.

\section{CASE - THE TAKE-OVER OF VISIO BY MICROSOFT}

In early 2000 Sydney based staff of Visio packed up the North Sydney office and moved to North Ryde to become employees of Microsoft. Microsoft had spent AUD \$2.27b to buy the company. Engineering and production at Visio had been based in the United States, so the Sydney office consisted mainly of a tight group of sales staff. Visio had one product, diagramming software for technical drawing and design in manufacturing (The Australian 2004).

The Sydney office of Visio had been relatively small in staff numbers but had had a wide responsibility, managing as it did marketing for the Asia Pacific region. The plan was to integrate the Australian sales arm into Microsoft proper, but allow the product development arm of the former Visio back in the U.S to operate as a separate division, notionally allowing its culture to continue to develop separately from Microsoft. 


\section{Figure 3 External indicators of internal cultures}

Visible features of a company that can be observed from the outside and can give indications of the likely themes in the internal culture include the following.

$>\quad$ The underlying structure of the business model including structural variables, such as:

○ inherent risk and the speed of reward or feedback as defined by Deal and Kennedy;

$\circ \quad$ the presence of knowledge workers and their values; and

○ inconsistencies between the basic missions of organisational units that may cause fragmentation.

Review

Responses by the company to critical incidents, which expose rationalities and ambiguities, such as change programs, accidents, strikes or responsiveness to strategic failures or opportunities; and

Basic management and operating practices, including reward system and reporting lines, which are symbolic reflections of underlying logics and priority schema.

Look at the annual reports as though they were a work of fiction that provides statements of the espoused culture, statements of purpose and manifestations of values.

Identify gaps between the espoused culture and the real culture by noting inconsistencies between public statements and performance in key areas

Map the arrangement of internal interest groups within both companies that are party to a prospective merger to imagine where subcultures might merge and reinforce one another.

The rational Visio salesperson should have been thrilled by the prospect of the Microsoft buy-out. Not only was Microsoft planning to release updated versions of Visio software, but the move to Microsoft would give sales staff access to a wider range of Microsoft suppliers, and of course the sales staff would have the opportunity to market the full range of products in the Microsoft suite, rather than the single product that they had been able to offer under Visio. (Computer Reseller News 2000). There would also be a new Microsoft web site to give customers information on the Visio products (Pennington 1999).

However, the cultural indicators put forward in Figure 2 suggest cause for concern about the cultural fit between the two companies. Microsoft is a huge global corporate bureaucracy, whereas the Sydney office at Visio had a small, socially tight team, in the younger demographic who identified strongly with the new and impressive product that they had to market. These factors created an upstart mentality, an aggressive approach to sales and a close team spirit.

In the lead up to the takeover the Microsoft camp were careful to maintain a single channel of communication between Microsoft and the Sydney office, vetoing wider communications between Visio staff and Microsoft employees. Microsoft provided a reassuring discourse with Visio staff, stressing that the companies were complementary and simpatico with one another, that everybody in Visio was valued by Microsoft and that there would be jobs for all. In addition, the product would maintain the Visio label. Visio chief financial officer Steve Gordon offered the comforting claim that "Microsoft intends to keep Visio operating as a division and there'll be lots of different opportunities for Visio staff" (Pennington 1999)

At the end of 1999, about 300 worldwide Visio sales staff went on a skiing trip together in the United States. For the Sydney office, the trip proved to be a last dance. Six months after the merger none of the Sydney sales staff remained with the new company. Staff did acknowledge the strong rational case for staying with Microsoft, but for them the bottom line was that the old Visio culture was gone. 


\section{CONCLUSION}

Microsoft might well have imagined that the culture of Visio was consistent with the culture to which it aspires: the work hard, play hard model. Indeed in buying Visio it was acquiring that that very culture. The experience of the Sydney office of Visio suggests that - at least with respect to its intangible assets - Microsoft had wasted its money. It had bought a sales expertise and a work hard play hard culture. However, the members of that culture, at some level of consciousness, applied the judgements implied by the indicators listed in figure 3 above. They saw a corporate bureaucracy with a process culture coming their way. Those who did not leave immediately suffered the culture shock soon after and left as soon as they realised that they were working within a culture that was foreign and unpalatable.

The indicators listed in figure 3 are backed by theory but remain to be tested. They are certainly not fool proof. They are simply indicators which can inform judgement. Such judgements might conclude that the internal life of a company is different to one's own internal life, but that these differences provide complementarities. Alternatively, an acquirer might actually be looking for a company to acquire that has the kind of organisational culture that the company is itself trying to promote within its own walls. Both these judgements might provide a rationale for going forward with the purchase. However, should the company making the prospective acquisition decide that the newly acquired culture is likely to be disruptive or barren, it might be better to look further a field at other acquisition targets. Either way, the company needs to know what it is buying. The fact that Microsoft tightly constrained the avenues for communication between the two companies prior to the merger suggests that it knew that the culture that it was about to buy would be both different and desirable. It further suggests that Microsoft was concerned that if Visio employees had been able to get an insight into the Microsoft monolith, they might have been spooked by what they saw. What is certain was that the knowledge, culture and leadership of the Sydney office walked out the door, leaving Microsoft with an empty shopping bag.

\section{REFERENCES}

1. Arnal, E., Ok, W., and Torres R., (2001) Knowledge, Work Organisation and Economic growth Labour Market and Social Policy Occasional Papers \# 50, Organisation for Economic Cooperation and Development, Paris

2. $\quad$ Collins J., and Porras J., (1996) Built to Last: successful habits of visionary companies Harper Business New York.

3. Computer Reseller News (2000) MS reveals vision for Visio. 19 April Vol 6 \# 510 March p8.

4. Deal T. and Kennedy A (2000) The New Corporate Culture revitalising the workplace after downsizing, mergers and re engineering Texere London.

5. Deal T., and Kennedy A, (1982) Corporate Cultures: the rites and rituals of corporate life Perseus, Boulder Co.

6. $\quad$ Drucker, P. (1998) The Discipline of Innovation Harvard Business Review, Nov-Dec, pp. 149-157.

7. $\quad$ Kotter J.P. and Heskett J. L., (1992) Corporate Culture and Performance, Free Press New York.

8. Lev B. (2001) Intangibles: management, measurement and reporting Brookings Institution Press Washington D.C.

9. Martin J (1992) Cultures in Organisations: Three Perspectives Oxford University Press London.

10. Martin J. and Meyerson D. (1988) Organisational Cultures and the Denial, Channelling and acknowledgement of ambiguity in Pondy L Boland and Thomas H. (eds) Managing Ambiguity and Change Wiley New York.

11. Peters T. and Waterman R. (1982) In Search of Excellence Harper and Row New York.

12. Smircich L (1983) Concepts of Culture and Organizational Analysis Administrative Science Quarterly Vol 28 \#3 pp. 339-358.

13. The Australian (2000) Microsoft buys Visio, 25 January 2000, p 41. 